\title{
A methodical procedure for designing consumer oriented on-demand IT service propositions
}

\author{
Henrik Brocke • Falk Uebernickel • Walter Brenner
}

Received: 21 May 2010/Revised: 15 October 2010/Accepted: 26 October 2010

(C) Springer-Verlag 2010

\begin{abstract}
IT providers are increasingly facing the challenge to adapt their previously resource oriented service portfolios in order to offer their customers services which explicitly support business processes. Such customer centric service propositions, however, seem to contradict the demand for standardized and automated operational IT processes more than traditional IT service offers, as they are even more subject to customer individual reengineering efforts due to permanently changing business requirements. In order to reconcile increased efficiency in operational processes and effectiveness in consumer oriented service propositions, we propose (1) to predefine all service propositions in consideration of both consumer oriented commitments and operational processes, and (2) to allow for standardized customization by offering a selection of complementary service propositions that extend commitments regarding customer oriented functionality and performance. Such service propositions are aligned with a company's entities such as workplaces. Thereby the customer organization is enabled to trace, control and adjust commitments, value and expenses of IT services per entity in its business. We introduce a procedural model for designing and on-demand requesting this kind of service propositions, and we illustrate the model's application and impact by examples taken from two large projects with an associated IT provider.
\end{abstract}

Keywords IT service design - Service proposition - Service agreement . Service system $\cdot$ Consumer focus $\cdot$ Self-service $\cdot$ Reference model

\footnotetext{
H. Brocke $(\bowtie) \cdot$ F. Uebernickel $\cdot$ W. Brenner

University of St. Gallen, Mueller-Friedberg-Str. 8, 9000 St. Gallen, Switzerland

e-mail: henrik.brocke@unisg.ch

URL: http:॥www.iwi.unisg.ch

F. Uebernickel

e-mail: falk.uebernickel@unisg.ch

W. Brenner

e-mail: walter.brenner@unisg.ch
} 


\section{Introduction}

In research on services the focus has recently been shifted toward continuous value co-creation and customer orientation (Van Bon 2007). The interdisciplinary research area of Service Science suggests an integrated consideration of flexible, customer oriented IT service management and design (Chesbrough and Spohrer 2006; Maglio et al. 2009). Correspondingly, this article focuses on consumer oriented management of ongoing IT service relationships between IT providers and customer organizations in order to accomplish effective IT support of customers' business processes. Thus, the work on hand refers to IT services as the cocreation of value in the customer's business processes through managing and processing information by means of information technology (cf. Rodosek 2003; OGC 2007a, p. 11). Correspondingly, hardware components and manual activities-i.e. 'resources' - may be involved for co-creating the value, but do not represent the sales units themselves (Zarnekow et al. 2006). While an IT service refers to the ongoing process of value cocreation (Spohrer et al. 2007), the precedent IT provider's related offering specification is called 'service proposition'. Consumer oriented IT services must fit customer individual demands and need to be specified in their value propositions (Grönroos 2000; Galbraith 2002). The rising demand for consumer orientation (Holub 2009), however, is a real challenge to IT providers (Unterharnscheidt and Kieninger 2010), as so far they have predominantly been offering technical IT services that focus on provisioning and maintaining IT infrastructure (Keel et al. 2007; Ernest and Nisavic 2007, p. 388).

At the same time, IT providers see themselves confronted with the need to streamline their operational IT processes in order to reduce cost and maintain their position in a highly competitive market (Metelko et al. 2008). Driven by bestpractice frameworks like ITIL (OGC 2007a) and CobiT (ITGI 2007), service provisioning processes are supposed to allow for repeatability, documentation, and automation. For this purpose, IT service propositions need to be clearly described and catalogued (Peppard 2003), and operational IT processes required for service provisioning need to be clearly specified. For further optimization and automation of service request processing, the use of customer self-service portals has been proposed (OGC 2007a). This would enable instant service contracting and dynamic service provisioning (i.e. on demand) as already on the rise with web services (Dan et al. 2004) and infrastructure services (Da Rold 2009).

However, a methodical basis for specifying standardized yet at the same time consumer oriented IT services is missing. Thus, this article addresses the research question as to how consumer oriented IT service propositions may be designed to enable standardized processing of requests of on-demand services. The study draws on Action Research as described in the next section. We give an overview on the traditional versus our proposed way of specifying IT services and subsequently introduce a procedure of designing consumer oriented on-demand IT service propositions. In effect, IT services may be agreed upon on demand by self service processes as we show in Sect. 5. Subsequently, we describe the application of service-dominant logic to IT service specification as the study's research basis. A discussion on the findings and their limitations concludes the article. 


\section{Research process}

The procedure model for designing IT service propositions has arisen from research done in two projects at one of the collaborating IT organizations over the last couple of years. As this work is characterized by direct interaction between academic researchers and representatives from the businesses involved, Action Research has been used as the underlying research paradigm (Whyte et al. 1991; Rapoport 1970). Built on direct and close interaction of researchers and practitioners (Gummesson 2000), Action Research involves practical application of methods and models (Argyris et al. 1982). Thus, it has frequently been used in applied information systems research (Baskerville and Wood-Harper 1998; Lau 1997) by linking theory and practice through an iterative process. In our studies two Action Research cycles were conducted, each one comprising five steps, as modeled by Susman and Evered (1978): diagnosing, action planning, action taking, evaluating, and specifying findings. Each cycle represents one voluminous, about 1 year research project with a cooperating multinational IT organization with revenue of nine billion Euros in 2009. The aim of both successive projects was a proof-of-concept of standardizing IT service management-at first by prototyping a solution (prototype project), and then by piloting it with customers of the IT organization (pilot project).

Striving for efficiency and effectiveness in managing flexible and adaptable IT service agreements, the aim was to develop two main outcomes of each project by methodical procedures: (1) a customer oriented, predefined portfolio of service propositions that covers individual demands and that allows setting up (2) a customer self-service portal supporting standardized service request processing via an ERP management system. Together, these outcomes would allow for on-demand management of IT service relationships. Adjustments of service agreements could be requested on demand likewise to industrial products and rendered by standardized operational IT processes. The customer self service portal is expected to make for transparency and consistency in the configuration of service agreements. Also, it allows flexible adaptation of service relationships and commitments deemed necessary due to changing customer requirements.

In the diagnose phase of the research cycles following Susman and Evered the authors analyzed some 450 catalog services and a number of comprehensive SLA arrangements at six IT organizations, including change requests and frame contracts. Due to formal and structural differences in the agreement specifications examined, analysis was limited to field notes identifying causes of change requests or insufficient transparency of service commitments. The authors also analyzed service design and contracting processes as well as extensions of contracted commitments along the service lifecycle. Four workshops and a couple of semiformal interviews with experts both from the IT organizations and from customer organizations helped ensure sufficient comprehension of agreements and challenges.

Subsequently, the authors reengineered the existing service design procedure and developed the procedure model presented in this article. The model follows the specification principles of Method Engineering (cf. Braun et al. 2005; Österle and Blessing 2000): Accordingly, techniques and tools facilitate roles in the execution of sequences of activities, which lead to specific results aiming for a certain value 
(Gutzwiller 1994). Having specified the procedure model as interplay of these units, six IT experts from the cooperating corporations were trained to be able to apply the model. The authors and business representatives then jointly developed service specifications that cover existing service relationships but allow also standardized service provision and transparency regarding business value. The procedure model was iteratively refined by the authors based on experiences, and two self-service portals were developed to leverage the potentials and opportunities resulting from increased transparency and consistency of service agreements. Expert interviews with representatives from both the IT provider organizations and their customer organizations were conducted to validate enhanced customer orientation and opportunities for operational process standardization. Aiming at cross-organizational feedback, six workshops, each one comprising several IT organizations, were held for review on the conceptual basis, the process, and the outcomes. Additionally, IT demand managers and users of IT support in five customer organizations gave feedback in interviews and paper-based questionnaires.

\section{Specification of IT services}

Building on the service life cycle frameworks of Garschhammer et al. (2001a) and Hegering et al. (1999), three stages can be identified that may affect IT service commitment specifications: service design, service contracting, and service usage (cf. Brocke et al. 2010a). Representing outcomes of the stages, IT service specifications (i.e. service propositions, service agreements and service arrangements) outline a number of functional and non-functional commitment properties (O'Sullivan et al. 2002). These outcomes are developed in certain activities that are performed by roles (i.e. types of people in organizational units). Figure 1 illustrates the procedure as an event driven process chain (EPC) in accordance with Scheer (2000; cf. Keller et al. 1992; Aalst WMPvd 2006).

At the stage of service design, IT providers traditionally specify a portfolio of resource oriented IT service propositions, such as provisioning and operating of servers, data storage, network operation, and other infrastructure focused services, as well as developing, maintaining and integrating software solutions (EITO 2007; Keel et al. 2007; Ernest and Nisavic 2007). This segmentation has originated from IT organizational structures that evolve around emerging technologies, offering
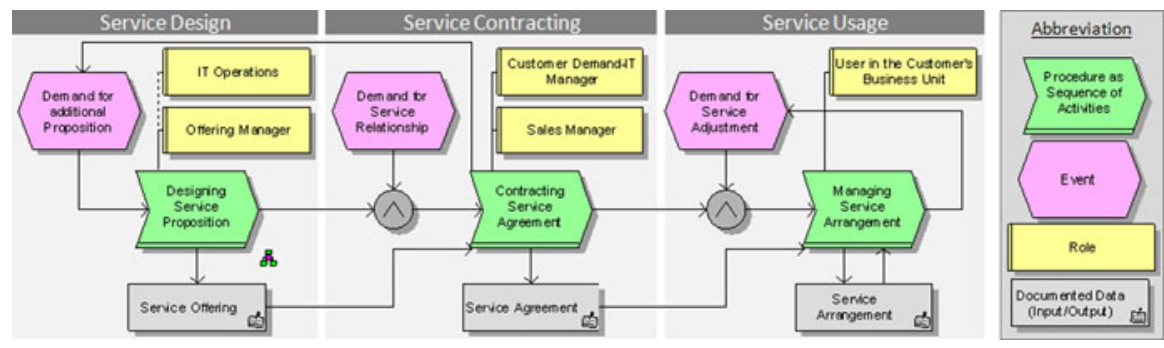

Fig. 1 Procedures and stages of IT service specification along the service life cycle [EPC notation] 
technology-specific services without taking into account business requirements (Winniford et al. 2009). Sales managers of IT organizations predominantly consider such service offering as a nonbinding contract template. Building on this template, the provider's sales managers and a customer's Demand-IT managers negotiate and concretize service properties with regard to output, responsibilities and conditions of IT services demanded. The outcome of such a service contracting process usually is a service level agreement (SLA; Sturm et al. 2000). Similar to IT service offers, SLAs usually cover commitments per 'infrastructural silo'-i.e. specific to categories of resources such as network, data center, and clients (Trienekens et al. 2004). Thus, supporting a business process by IT builds on a number of SLAs, while commitments in SLAs may affect several business processes. Once provisioned and in operation, IT services are continuously provided at the stage of service usage. However, as business requirements may change during the validity period of an SLA, changes in commitments may be proposed as change requests (Garschhammer et al. 2001a). They extend the contractual relationship and usually specify a change in the infrastructure resources allocated (OGC 2007c, p. 46f.). Together, SLAs and associated change requests represent the contracted 'service arrangement', i.e. the overall assembly of commitments.

In all organizations analyzed the challenges identified with regard to transparency of service commitments, value proposition and expenses were quite similar. Also, the fact that services and processes are highly customized and in no way standardized was found in the organizations under investigation.

As a result of the service design and contracting process, IT providing organizations may agree upon highly customized service arrangements. However, they risk facing two major difficulties, as the diagnosis of IT organizations analyzed in this study verified.

Lack of transparency in commitments and their value propositions: As resource oriented service propositions - the way they are typically offered by IT service providers-lack transparency in business value proposition, discrepancies between contractual parties with regard to the perception of and expectations regarding the services committed may occur (Trienekens et al. 2004; Rands 1992; Zeithaml 1988). Moreover, as SLAs mainly are supposed to ensure legal security for contractual partners, the "hodgepodge" of service arrangement documents that reference and extend each other is barely readable and misses essential elements (Karten 2004). Efficient management and continuous adjustment of IT service arrangements requires checking consistency in interdependencies and ensuring compliance of additional service requests and the overall service arrangement.

Lack of standardization and efficiency in operational processes: Individual negotiation of service arrangements requires not only a lot of time and human resources, but also counteracts the effort to achieve standardization of IT operational processes, which is why today in IT operations "informal work [is] prevalent" (cf. Barrett et al. 2004; Maglio et al. 2006). The situation is further aggravated by the fact that customer requirements usually change over time (Kannan and Proenca 2010; Alter 2006). Thus, continuous adaptation of service agreements to changing requirements is demanded (Ivens 2005). Efforts caused by changes in existing service arrangements constitute a significant part of the overall 
costs for IT operations, amounting to about $80 \%$ of total IT costs (Kaplan et al. 2008). Furthermore, commitments on operating specific resources constrain IT providers in the way they leverage their resources in order to optimize their IT operations.

Addressing these challenges, the procedure model presented in this article aims at allowing on-demand contracting and provisioning of services. To this end, IT service portfolios should consist of consumer oriented and predefined standardized service propositions that may be selected instead of being negotiated. Predefined at the stage of service design solely, such service propositions are supposed to cover all possible adjustments of ongoing service relationships with regard to the functional scope, the quality level, and the number of service recipients. In order to meet demands for customization, modular based concepts from industrial mass customization (cf. Pine 1993; Kaplan and Haenlein 2006) were adopted (cf. Brocke et al. 2010a) to offer a range of modularized commitments. Thus, a customer may arrange the IT services to be provisioned-i.e. the service arrangement-by requesting additional, modular commitments. They are offered as a selection of complementary service propositions. By such commitments furthermore the focus is shifted from the sources of the services (i.e. infrastructural silos) to its receivers (i.e. entities in the business domain). Commitments regarding consumer oriented functionality and performance properties then refer to such business entities instead of resources and provisioning activities. Thus, IT service commitments as well as their value propositions and expenses can be identified for each entity by selecting predefined service propositions.

Once designed, service propositions are no longer specified but can only be selected in the subsequent stages, i.e. service contracting and service usage. At the stage of service contracting, sales managers support the customer's Demand-IT department in putting together a pre-selection of service propositions deemed suitable and relevant to support given business requirements. Therefore, the service agreement consists of a number of predefined service propositions from the IT provider's portfolio, which later at the stage of service usage may be requested on demand. Only in case a customer's specific demand cannot be covered by a given portfolio of service propositions, the procedure of designing additional service propositions may be initiated and run through (see top left arrow in Fig. 1). Thus, predefinition of working instructions and standardized processes for every single service proposition offered and agreed upon is ensured.

At the stage of service usage, the customer's business units themselves may assemble the IT service arrangement to be provisioned by selecting and configuring service propositions as preselected in the service agreement. In doing so, the customer may continuously adjust commitments of the service relationship on demand. Thus, the service arrangement consists of a number of selected and parameterized instances of service propositions (i.e. service instances) that represent commitments agreed upon.

Predefinition of these service propositions in operational IT processes allows for standardized and repeatable on-demand request processes without further negotiation. To this end, it all depends on designing IT service propositions that allow standardized customization in a consumer oriented way. Our proposition of a 
facilitating procedure model for designing appropriate service propositions is outlined in the following section.

\section{Designing consumer oriented on-demand IT service propositions}

Designing predefined consumer oriented on-demand IT service propositions poses a challenge in terms of covering all individual customer demands by modular complementary commitments. One issue that needs to be clarified is the scale basis to be used for measuring the scope and volume of services as well as the expenses, as units traditionally used (e.g. data size, bit rate or work-hours) are not appropriate to be applied in this context (Edvardsson and Olsson 1996). For example, changing the time period of monitoring hardware per se does not add value for the customer and has no direct business relation. Only if transferred into a service offering of higher availability of the overall IT support, the customer has the ability to quantify the value of the proposition for their business (Oliva and Kallenberg 2003). The same is true for resource oriented performance definitions. Giving the customer the opportunity to customize a commitment on the basis of a network's jitter parameters does not comply with the customer's core competence and does not enable them to make reasonable decisions. As a result, the customer organization cannot manage or allocate IT expenses on the basis of resource usage. Imagine a cost cutting decision by the customer's management to reduce the amount of data stored or the number of SAP transactions. Instead, a scale-basis (i.e. cost drivers and volume drivers) has to be identified that (1) represents variability of the business situation (2) is controllable through decisions by the customer's management, and (3) directly affects the capacity and resources required to provide the services.

Addressing the identification of an appropriate scale-basis as one essential activity, the procedure model part of service design is outlined in the following. It is detailed in its activities as well as in their outputs, inputs and the roles involved as illustrated in Fig. 2.

The part of service design in the procedure model comprises four major activities, each one of which will be explained in the following subsections.

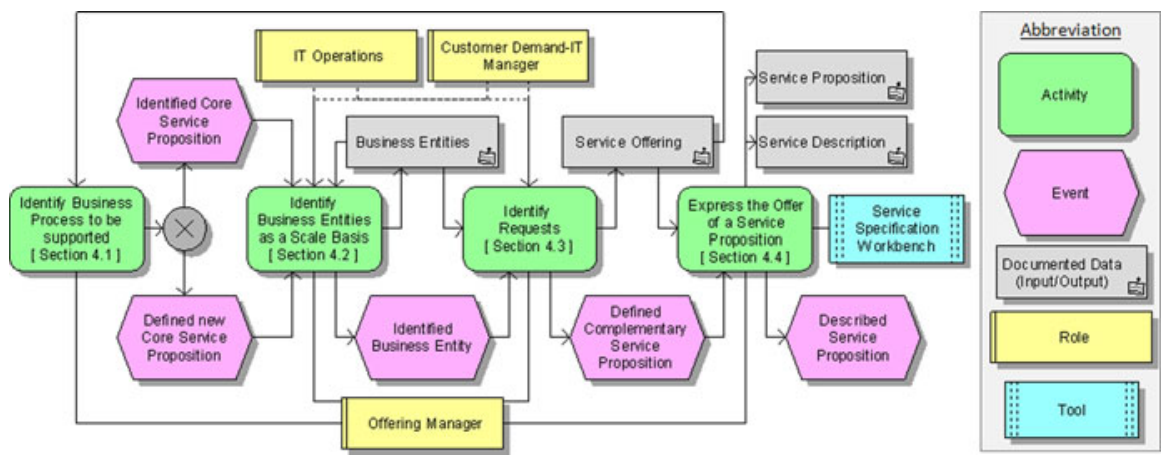

Fig. 2 Procedure model part for designing consumer oriented on-demand IT service propositions [EPC] 
Initially, the business process to be supported by IT needs to be identified or specified, respectively, if it is not offered as a core service yet. Then, an adequate scale basis of service per business process is to be identified. Additional requests for customization of the service with regard to functional and performance commitments result in complementary service propositions that refer to a scale basis. As a last step, the service proposition identified is described in its commitments, parameters and interdependencies in detail. The activities are executed by the IT provider's offering managers, though in some parts, IT operational managers and the customer's Demand-IT department is involved as advisors.

As the procedure model was applied in the course of two Action Research projects with a multinational IT providing organization, each activity description refers to examples of outcomes of two significantly different IT service segments, of which both represent quite sophisticated business relationships with regard to the sharing of responsibilities.

The first service segment, as examined in the initial prototype project, addresses the end user who is to be supported in their business processes when working as a merchant or as an accountant. Therefore, all IT based functionalities required are to be bundled in order to deliver the predefined value proposition. This includes provision of storage and application hosting as well as network and client provision. If one of the components fails to deliver, the whole commitment is considered a default. Due to that characteristic, this industry solution is called end-to-end service, following Saltzer et al. (1984).

The second service segment was examined during the pilot project and provides basic IT infrastructure and application operations. Here, IT service propositions address IT organizations' customers, which are IT organizations themselves. They are offered provision and maintenance of middleware components in order to host their application programs. The customer IT organizations in turn provide application programs and associated deployment data for releases. Although less related to the business processes of end users, even these basic service propositions may focus on customer centric entities rather than on resource specifications. Complementary service propositions may govern customizability, especially regarding roll-outs of further applications as well as complex interactions of data delivery and approvals of release change requests. To distinguish this offering from the end-to-end service introduced above, it is labeled B2B hosting.

\subsection{Identifying business process support as a core service proposition}

Customer organizations create value by executing business processes. Hence, IT service commitments should explicitly refer to specific business processes in order to achieve transparency in IT's value proposition for the customer's business. As a first activity, abstracting from details on resources and implementation (Garschhammer et al. 2001b) IT support of business processes has been identified. Basic support of each business process is to be offered as a 'core service proposition'.

Examples of core service propositions from the prototype project refer to daily transaction processes of merchants and accountants. The commitment to support e.g. accountants in their process includes provision of storage and application 
hosting but also provision of networks, workplace clients etc. If one of the components fails to deliver, there will be a breach of the end-to-end commitment, since the intended value could not be created.

Although less obvious, there are also resource specific service relationships positioned at early stages in the IT service value chain which support specific business processes occurring at later stages. Exemplarily, in our pilot project, basic hosting services were demanded by the customer IT organization to support business processes of its customers (in this case, accounting and expense report processes). Thus, the core service proposition to be identified is not the provision of application components for the customer IT organization but one essential part of supporting the customer's customer processes (here: application hosting for accounting and expense report processes).

\subsection{Identifying business entities as a scale basis of the service}

Changing business requirements and variations in the process usage necessitate changes with regard to resource capacity, such as storage space, licenses, backup capacity, clients etc. required to provide IT support for business processes. But instead of directly offering and pricing resource capacity, which is common today (Wittgreffe et al. 2006), the approach presented in this work aims at finding a scale basis that reflects the customer's organization on the basis of the number of customer oriented entities. In this context, business entities represent selected objects in the customer's business domain that have a direct effect on the amount of and costs for capacity and resources needed to provide the service. Along with actual business entities, the scope and volume of services as well as efforts and resources required would vary depending on the customer organization and its business situation. Furthermore, scope and volume of services can be controlled by management decisions of the customer organization. Acquiring a service proposition to add, change or terminate service for a business entity would lead to the installation and operation of IT infrastructure. Since the customer organization has a direct competence in and influence on its business entities, expenses for IT become traceable, relatable and manageable.

The separation of responsibilities in a service relationship works as an indicator for such business entities in IT service design, as it predefines which properties and data have to be provided and adjusted by the customer in order to render the IT service. For example, in the hosting service project the customer provides the applications and specifies necessary database interfaces and new releases to be deployed. The IT provider uses the provided data to configure the infrastructure accordingly. The number of applications, interfaces or releases has a direct impact on the IT provider's effort to render services. Therefore, IT operations managers, service offering managers and the customer's Demand-IT department jointly identified these objects as relevant business entities in this service relationship. In contrast, contracting on the basis of numbers of servers, licenses and other resources is not in the responsibility of the customer and has to be accounted by the IT provider. 
Normally, the amount of IT resources required for operating services varies according to the size of the customer organization. As it is also in the responsibility of the customer, its organizational structure may indicate additional relevant business entities. A change in the organizational structure (leading to an extension of the number of users of a core service, for example) may induce both initial efforts, like the setup of user accounts, and continuous efforts, like the number of allocated licenses and the scope of traffic on the infrastructure to be provided. With regard to the hosting service, the number of users of an application works as a scalebasis for middleware capacities.

Especially in end-to-end offerings, entities in the organizational structure as modeled by Scheer (2000, p. 56) have emerged as suitable scale-basis: countries and locations require network access, workplaces are to be provided with desktop clients, and employees require initial system registration.

The outcome of this activity is a collection of business entities that can be controlled and adapted by the customer and drives efforts in operating IT services. Figure 3 lists examples of business entities and illustrates instances of entities that work as a scale basis for IT support of expense report processes. The collection may serve as reference sample for identifying relevant business entities in other contexts. The examples of entity instances visualize a scenario in which a business unit for accounting (named Alpha) demands for IT support of its expense report process. An IT provider of end-to-end services (named Beta) supports the business unit's users, workplaces, locations and countries with IT services, i.e. provides user administration, desktops, local and wide area networks, and application programs for accounting. In order to keep these application programs running, Beta sources basic hosting services from IT provider Gamma. Middleware components are operated by Gamma, but selected and configured by Beta in order to provide services for Alpha's business processes. Additional application programs, middleware configuration as

\begin{tabular}{|c|c|c|c|c|}
\hline $\begin{array}{l}\text { Business } \\
\text { Entity }\end{array}$ & $\begin{array}{l}\text { Provided data by } \\
\text { customer }\end{array}$ & Impact on service efforts & $\begin{array}{l}\text { Interdependencies } \\
\text { with }\end{array}$ & $\begin{array}{l}\text { Example of interdependent } \\
\text { instances of Business Entities }\end{array}$ \\
\hline $\begin{array}{l}\text { Business } \\
\text { Process }\end{array}$ & $\begin{array}{l}\text { Process selection, } \\
\text { responsible user }\end{array}$ & $\begin{array}{l}\text { Customer on-site and remote } \\
\text { support, basic service config. }\end{array}$ & $\begin{array}{l}\text { other Business } \\
\text { Processes }\end{array}$ & B-Process \\
\hline $\begin{array}{l}\text { User I } \\
\text { Administrator }\end{array}$ & $\begin{array}{l}\text { User properties and } \\
\text { rights, home location }\end{array}$ & $\begin{array}{l}\text { Registration; occupied user- } \\
\text { licence; traffic }\end{array}$ & $\begin{array}{l}\text { Workplace; Location I } \\
\text { Application }\end{array}$ & \begin{tabular}{|l|} 
Administr. \\
G. Dockhorn \\
\end{tabular} \\
\hline Workplace & $\begin{array}{l}\text { Place of location, } \\
\text { responsible user }\end{array}$ & $\begin{array}{l}\text { Client provision and } \\
\text { maintenance; Network access }\end{array}$ & $\begin{array}{l}\text { Location, responsible } \\
\text { User }\end{array}$ & \begin{tabular}{|c|} 
Workplace \\
OL 392
\end{tabular} \\
\hline Location & $\begin{array}{l}\text { Address properties, } \\
\text { responsible user }\end{array}$ & WAN access & $\begin{array}{l}\text { Country; responsible } \\
\text { User }\end{array}$ & $\begin{array}{c}\text { Location } \\
\text { Dublin }\end{array}$ \\
\hline Country & Country selection & $\begin{array}{l}\text { Compliance with data } \\
\text { processing law }\end{array}$ & Process & $\begin{array}{l}\downarrow \\
\text { Countrv } \\
\text { Ireland }\end{array}$ \\
\hline Application & $\begin{array}{l}\text { Application program } \\
\text { data }\end{array}$ & Deployment efforts; data storage & $\begin{array}{l}\text { Process, Middleware, } \\
\text { User Amount }\end{array}$ & Application \\
\hline Release & $\begin{array}{l}\text { Release script; } \\
\text { deployment instruction }\end{array}$ & Deployment efforts; data storage & $\begin{array}{l}\text { Application, } \\
\text { Middleware Comp. }\end{array}$ & \begin{tabular}{|c||} 
S.Release \\
6.323 \\
\end{tabular} \\
\hline $\begin{array}{l}\text { Middleware } \\
\text { Component }\end{array}$ & $\begin{array}{l}\text { Middleware selection } \\
\text { and configuration }\end{array}$ & $\begin{array}{l}\text { Middleware provision and main- } \\
\text { tenance; configuration efforts }\end{array}$ & Application & \begin{tabular}{|c|}
$\frac{\downarrow}{\text { Middleware }}$ \\
WP WTX \\
\end{tabular} \\
\hline Interface & $\begin{array}{l}\text { Configuration script; } \\
\text { deployment instruction }\end{array}$ & $\begin{array}{l}\text { Deployment efforts, database } \\
\text { configuration }\end{array}$ & Application & \begin{tabular}{|c|} 
Interface \\
DB-icsl \\
\end{tabular} \\
\hline Abbreviations: & \multicolumn{4}{|c|}{$\begin{array}{l}\text { Business Entity of Alpha, supported with IT by Beta } \\
\text { Business Entity of Beta, supported with IT by Gamma }\end{array}$} \\
\hline
\end{tabular}

Fig. 3 Example of relevant business entities for 'hosting' and 'end-to-end' service relationships 
well as new interface or release deployments represent effort drivers for Gamma and a scale basis for Beta's service demands.

\subsection{Identifying requests per business entity}

In order to enable standardized processing of possibly every interaction with the service provider as a self-service process, all change requests should be predefined as service propositions. Such requests for changing an existing service relationship may either emerge if changes with regard to relevant business entities or their number occur, or if requirements with regard to function or performance evolve. As a consequence, we differentiate between administrative requests and functionality or performance related requests (cf. Vaattovaara 1999). Since commitments are supposed to vary with business entities, each service proposition references to a specific business entity. A collection of service propositions represents the outcome of this procedure's activity as shown in Fig. 4. As a supporting technique for executing this activity, existing collections may serve as reference models for aggregating, specializing or analogously specifying a new one (cf. Brocke et al. 2010b).

Administrative requests: As customer organizations change and develop during the time of an IT service relationship, also the number of business entities may change. By definition, these changes impact IT operational efforts in service capacity. In order to manage service relationships on the basis of business entities, all administrative change requests to register, provide, or terminate services for a specific business entity need to be standardized as service propositions. For example, additional employees and workplaces involved in a customer's business process may require additional licenses, storage space, clients, and other resources. But instead of requesting these resources, the end-to-end service model of the prototype project enables the customer organization to request the registration of additional users and the provision of additional workplaces. Regarding the hosting

\begin{tabular}{|l|l|}
\hline \multicolumn{2}{|c|}{ Basic Hosting Support for Accounting } \\
\hline Application & HA111 Deploy an Application \\
\hline Application & HA112 Remove an Application \\
\hline Middleware & HA122 Configure a certain Middleware for Appl. \\
\hline Interface & HA131 Configure an Interface to Certain Database \\
\hline Release & HA141 Deploy a new Release \\
\hline Application & HA212 Execute Application-Update transport \\
\hline Middleware & HA221 Execute Basic Component - Deployment \\
\hline Interface & HA231 Interface Data Archiving \\
\hline Application & HA311 Extended Provisioning \\
\hline Application & HA312 Extended Support of Application-Users \\
\hline Application & HA313 Change User Amount \\
\hline Application & HA314 Additional Incident Management Level \\
\hline
\end{tabular}

\begin{tabular}{|c|l|}
\hline \multicolumn{2}{|c|}{ IT-Support for Merchants and Accountants } \\
\hline Company & MA111 Terminate IT-Support for Merchants \\
\hline Country & MA121 Provide Core Service-Access at a Country \\
\hline Location & MA131 Provide Core Service-Access at a Location \\
\hline Workplace & MA141 Provide Core Service Access at Workplace \\
\hline User & MA161 Register User for Core Service Access \\
\hline User & MA162 Remove User from Core Service Access \\
\hline Location & MA331 Extended On Site Support Period \\
\hline Location & MA332 Fast Operations in Merchandising Tasks \\
\hline Company & MA411 Special Reports \\
\hline Workplace & MA441 Extended display \\
\hline User & MA461 Online Backup Personal Data \\
\hline User & MA462 Shared Data Storage Space \\
\hline
\end{tabular}

Fig. 4 Examples of service propositions to manage business entities for two core service offerings 
scenario, additional configuration of a specific middleware component or interface is defined as an administrative service proposition. Thus, such service propositions configure a new business entity as an additional service receiver.

Functionality related requests: Requirements on functional IT support of business processes may vary depending on the customer organization, time, and business entity. In this context, customer centric functionality is not limited to the functionality of application programs but covers all functionality aspects of IT support of business processes, such as sharing data, generating reports, or providing extended displays for selected workplaces. In order to configure the service relationship according to the customer's demands, complementary service propositions allow requests of such functional extensions on demand. Extended functionality can be selected per business entity, as the example of extended displays shows. Acquiring such a complementary proposition by referencing to a specific workplace would increase IT expenses for that specific business entity only. Thus, transparency regarding both business value and expenses would be increased.

Performance related requests: Similar to functionality related requests, it is the customer's responsibility to continuously adjust performance commitments according to changing business requirements. However, customer centric performance parameters do not include resource oriented capacity, continuity, and latency (OGC 2007b; O’Sullivan et al. 2002), but typical quality parameters of general process management such as process abortion rate and periods of usage time of process support with IT.

Also similar with functionality related requests, the need for performance parameter values can vary with and reference to a specific business entity. For example, availability of on-site support may vary depending on the specific location. A permanent or temporary upgrade for a specific location may then be offered as a complementary service proposition to increase availability as well as IT expenses for that specific object only. The same concept works with a change, update, or optimization of other performance issues, as long as the selected business entities directly incur costs for changed efforts in IT-operations.

As a result, the service agreement's commitments can be customized in detail. Requesting the adjustment as priced complementary service proposition allows analysis and control of IT expenses per business entity within a customer's organization.

\subsection{Expressing the new offer of a service proposition}

Having identified necessary service propositions to be offered, these propositions have to be described in detail. In order to gain explicit 'optionality' (cf. Thomas and Brocke 2010), each of the service propositions needs to be clearly expressed a priori with regard to interdependencies with other propositions, individualization parameters and information requirements, functional and non-functional commitments, and cooperation obligations (Brocke et al. 2009).

Interdependencies: In the last section different kinds of service propositions were identified. While administrative service propositions may configure new business entities, other propositions reference to existing business entities for extending or 
changing commitments in functionality and performance. Thus, the latter may only be requested if the former have already been acquired. In other words, service propositions may be dependent on the existence of service instances. Such dependencies in what service propositions need to be given in order to be allowed to request additional service propositions are specified in dependency matrices of service propositions.

Parameters: Striving for efficient IT operational processes, all customer individual data and characteristics of a service instance are indicated by the customer in the process of service requesting and serve as parameters for service provisioning. Examples of parameterization are e.g. address data of relevant business entities, the customer's role concept, or design of reports but also deployment data and scripts of interfaces or releases to be deployed. Such data is prompted as text, templates, or script uploads, adapting the service propositions to the customer's business entities when they are instantiated. Likewise, references to other service instances as formulized in the dependency tables are to be entered as parameters when requesting a new complementary service proposition. Thus, all data necessary for standardized service request processing are prompted at the point of service request.

Commitments: Each service proposition is being described in its functional and non-functional commitments. They have a binding character and declare outcomes and value propositions. In contrast, descriptions of activities, provisioning processes or technical implementation are not committed to the customer but only expressed for internal IT operations. Quality parameters are defined in measurement procedures and committed to the customer from the user's point of view. As an example, data loss probability and backup interval are translated to 'hours of lost work' (cf. Brocke et al. 2009). Consequences in case of failures and exceptions are specified in a master agreement.

The description of service propositions are documented in a catalogue as proposed by ITIL (OGC 2007a) to serve consumers as a vehicle to proactively select the service propositions that suit their needs. The descriptions developed within the introduced projects amount to 239 pages, of which an extract is published by Brocke et al. (2009, Fig. 2). An XML-meta language was defined on the basis of a schema for specifying web service agreements called 'WSAgreement' (Andrieux et al. 2007). It is serving as a data source for the generation of catalogs as well as interfaces to self-service portals and business specific information systems.

In order to support the activity of service proposition specification by means of a tool, an application has been developed in the scope of the two projects. The tool supports the service offering manager in reusing existing specifications of commitments as text modules when defining a new service proposition. Thereby, time-efforts for specifying new service propositions are reduced and readability is enhanced (Ament 2003). Aiming for a consistent data basis throughout the ITorganization, the application has been developed in SAP and thus enables the entries of service propositions to be linked to later service agreements and arrangements as well as the related the installed base of resources. 


\section{Impact on managing IT service arrangements}

Having designed consumer oriented on-demand IT service propositions by means of the procedure model introduced, the impact on the management of IT service arrangements at the usage stage is twofold. Firstly, customers become able to trace service arrangements with regard to committed functionality and performance as well as related expenses per business entity and process. Secondly, adjustments of service arrangements may become standardized with regard to both on-demand request processing and service provisioning. As a single common user interface, a self-service portal seems suitable to support both traceability of ongoing service arrangements and configuration of consistent and fully parameterized complementary service requests (Tien and Berg 2003; Archer and Yuan 2000).

Two self-service portals have been implemented in the scope of the projects executed in the research process as detailed by Brocke et al. (2011). The portals make use of service interdependencies defined at the stage of service design (cf. Sect. 4.4) for displaying service arrangements in a tree structure showing the total of commitments. Thus, the customer may trace the requested IT service instances according to referenced business entities and aggregate their expenses. Detailed information may be reported per service instance concerning agreement history and especially compliance of performance parameters, i.e. failures and exceptions in service provisioning over time.

In reaction to customers' business requirements changing, IT service arrangements may be adjusted on demand by selecting and requesting predefined complementary service propositions by means of a self-service process. Aiming at standardized and efficient service provisioning, consistency with the actual service arrangement may be ensured with the help of the self-service portal. Additionally requested service propositions are referenced to services already agreed according to service dependency tables. For example, requesting a service period extension would require a reference to a service instance that already provides IT support for a specific location of the customer's business. The customer is supported in consistently adjusting the service arrangement. Building on the generated view on the existing service arrangement, the customer may select a singular service instance that is to be changed or extended in its commitment. In response, the view on the service propositions offered reduces the offering to those propositions that may be requested in this context taking into account service dependencies. The portal user may then select and configure a service proposition. The configuration is proved by the portal in validity and completeness according to specified parameters and dependencies declared in the service design stage (cf. Sect 4.4). If the configuration is valid and complete, it may be requested in order to modify the service arrangement as configured. If, for example, the customer wants to extend the availability of the on-site support for his office in Dublin, the portal user may select the service instance that provides the support of the location within the service arrangement. The user may then select and configure "extended service support" as one of several valid service propositions in this context. The customer then enters specific information and requests the resulting modification of 
commitments. As all the processes are predefined, the request results in standardized processes of service provisioning.

\section{Related work: service science as a basis for designing consumer oriented on-demand IT service propositions}

Due to its interdisciplinary approach, research in flexible, consumer oriented IT service management and design is considered an integral part of Service Science (Chesbrough and Spohrer 2006; Maglio et al. 2009). Being a paradigm in Service Science research, service dominant logic (S-D logic) focuses on the exchange of competences as a basis for co-creation of services and shifts value creation from the producer toward a collaborative co-creation process of service outcome (Vargo and Lusch 2006; Bitner et al. 1997; Wikström 1996). This mindset comprises a shift from thinking about value in terms of technical oriented, tangible operand resources to processes and competences as operant resources that are capable of creating value (Vargo and Lusch 2004; Constantin and Lusch 1994).

Aiming at managing IT service specifications from a service oriented perspective, this research builds on the application of S-D logic as a new view on the IT sector.

In this sense, IT service would not be seen as a unit of output but as a process of value co-creation for and with another party with a relational focus. Instead of delivering one-time services through executing an action like a release deployment or configuration, the IT provider may propose its expertise to effectively co-create value in an ongoing relationship. Furthermore, IT value propositions would be committed instead of providing infrastructure, allowing continuous improvement of operational IT processes. These characteristics imply a shift from transactional, resource driven IT services toward relational, consumer oriented service propositions to co-create value over a period of time.

In our studies we have implemented these shifts by (1) establishing the opportunity to continuously manage ongoing service relationships and maintain transparency in the service agreement, and (2) building service relationships on consumer oriented service propositions.

We have therefore adopted Spohrer et al. (2007) construct of service systems as "value co-production configurations of people, technology, other internal and external service systems, and shared information". In our studies, each service relationship between an IT provider and a customer organization represents such a service system as an ongoing and "dynamic configuration of resources [that] create[s] value" (Maglio et al. 2009). The claimed dynamics of configured resources required us to design service propositions that abstract from details on resources and implementation and offer consumer oriented value propositions instead. The procedure model we introduced results in complementary service propositions with regard to changes in functionality, quality, and business entities affected, without committing technical implementation issues. Contracting on outcome rather than on resources, activities and tasks has already been identified as driver for S-D logic by $\mathrm{Ng}$ et al. (2009). Applied on IT service propositions, the IT provider is no longer 
restricted by commitments on infrastructure regarding flexible resource management and optimization, while the customer is enabled to identify and understand value and expenses of IT in their business.

The resulting flexibility is especially important as relational service systems may vary over time in conditions, usage, and requirements (Kannan and Proenca 2010; Alter 2006). Existing life cycle approaches that handle evolving service systems (Alter 2008) and requests for change (OGC 2007c) predominantly execute changes via development projects. However, such a procedure is accompanied by individual agreements that are charged per working hour and resource efforts and contradict the demand for standardization in IT operations. In order to cover this aspect, our approach of managing IT service arrangements enhances the research field by suggesting standardized on-demand request processing of predefined service propositions by means of a self-service process. As IT operational processes and customer data to be provided are predefined for each service proposition this approach applies design of service systems as postulated by Glushko and Tabas (2009) in order to bridge customization at the point of sales and standardized service creation.

With regard to our procedure model for designing consumer oriented on-demand IT service propositions, related work concerning methods for service design within the context of Service Science generally builds on the findings of the matured research domain Service Engineering (Bullinger et al. 2003). This domain is now reflected in the research term Service Science, Management and Engineering (SSME; Maglio et al. 2006), which represents an academic initiative (Galup et al. 2009) in the field of IT-Service Management (Van Bon 2007). Indeed, existing models seek to systemize and improve the process of service development (e.g. Ramaswamy 1996; Bullinger and Scheer 2006, p. 119) but reveal considerable weaknesses with regard to the level of detail, practical orientation, and configurability of customers' demands (Bullinger et al. 2003, p. 10; Kunau et al. 2005, pp. 192; 196). Our studies address this research gap by introducing a procedure on how to design consumer oriented, configurable, yet at the same time standardized service propositions. As a reference model (Fettke and Loos 2003) its reuse is supposed to increase both effectiveness and efficiency when being applied or adapted in specific situations (Becker et al. 2004).

\section{Conclusion}

Due to customer specific and evolving conditions, ongoing IT support of business processes requires customization and continuous adjustment of IT service arrangements. However, individually negotiated SLAs and change requests impede efficient operational IT processes, while the focus on infrastructure leads to discrepancies regarding the perception of and expectations regarding services committed and costs incurred.

In order to balance standardization and customization, we introduced a methodical reference procedure for designing and arranging consumer oriented IT service propositions that at the same time allow for standardized on-demand service 
request processing, provisioning and operations. Predefined service propositions enable customization of commitments with regard to functionality, performance, and objects as receivers of services. To this end, service arrangements consist of parameterized instances of service propositions. They may be adjusted to changing business requirements by requesting complementary service propositions. Alignment of these service propositions to customers' business entities allows them managing IT service commitments according to business entities, with services being individually tailored to requirements per entity and incurred expenses becoming traceable and relatable to business value.

Our approach builds on basic premises of S-D logic as it shifts the understanding of the term 'service' from technical oriented, tangible and operand resources toward relational co-creation processes that create value in ongoing service systems through IT support of business processes. Our studies contribute to research in Service Science by concretizing a procedural reference model for designing on-demand service propositions that enables standardized request processing by means of customer self-service processes.

Repeated implementation of this methodical procedure has experienced high acceptance in customer organizations: based on interviews and paper-based questionnaires, representatives from these organizations attested significant (full points scored) impact of the resulting service models on traceability and changeability of service arrangements as well as effects on diversification and customer loyalty. Moreover, IT operations experts confirmed increased standardization capabilities when applying the procedure model in interviews.

Nevertheless, our procedure model as well as our studies inhibit some limitations. Limits of the procedure model must be stated with regard to IT service type. Having shown its implementation for industry specific end-to-end solutions as well as traditional IT infrastructure and applications operations, limits occur when it comes to offering individual application development, system integration, and consulting services. While person day rates usually is the scale basis of such services, the related scale basis would contradict the paradigm of customer oriented scaling of services. Existing research in use case points or function points (Ebert et al. 2005) could be used to extend our approach to that kind of IT service. With regard to limits of our studies, it must be said that the number of cases the method was applied for is small (though taking place in very large projects). Our research could further be extended by thoroughly analyzing a sufficient number of IT providers to further evaluate the challenges in managing customization and continuous adaptation of IT service specifications. The measurement of success does not build on quantitative data and is not independent from environmental factors. Analysis of long-term effects on a number of IT providers applying the approach would enable analysis on more quantitative data and advance our research. Moreover, the self-service portal introduced is limited to managing IT service relationships comprising only one single IT provider. While this is sufficient for implementation at organization internal IT providers, consistent integration of multiple providers' service propositions remains a task to be dealt with.

Considering these limitations, the real life cases executed in an Action Research approach show that the procedure model for predefining consumer oriented and 
modular IT service propositions contributes to both transparency in service arrangements and efficient on-demand processing of service requests.

\section{References}

Aalst WMPvd (2006) Formalization and Verification of Event-driven Process Chains. Department of Mathematics and Computing Science, Eindhoven University of Technology, Eindhoven

Alter S (2006) The work system method: connecting people, processes, and IT for business results. Work System Press, Larkspur

Alter S (2008) Service system fundamentals: work system, value chain, and life cycle. IBM Syst J 47(1):71-85

Ament K (2003) Single sourcing—building modular documentation. William Andrew Publishing, Norwich

Andrieux A, Czajkowski K, Dan A, Keahey K, Ludwig H, Pruyne J, Rofrano J, Tuecke S, Xu M (2007) Web services agreement specification (WS-Agreement). Global Grid Forum, Muncie

Archer N, Yuan Y (2000) Managing business-to-business relationships throughout the e-commerce procurement life cycle. Internet Res 10(5):385-395

Argyris C, Putnam R, Maclain Smith D (1982) Action science—concepts, methods and skills for research and intervention. Jossey-Bass, San Francisco

Barrett R, Kandogan E, Maglio PP, Haber EM, Takayama LA, Prabaker M (2004) Field studies of computer system administrators: analysis of system management tools and practices. In: Proceedings of the ACM conference on computer supported cooperative work, Chicago, IL, 06-10 November 2004

Baskerville R, Wood-Harper T (1998) Diversity in information systems action research methods. Eur J Inform Syst 7(2):90-107

Becker J, Delfmann P, Dreiling A, Knackstedt R, Kuropka D (2004) Configurative process modelingoutlining an approach to increased business process model usability. In: Proceedings of the information resources management association conference, New Orleans, LA, 23-26 May 2004

Bitner MJ, Faranda WT, Hubbert AR, Zeithaml VA (1997) Customer contributions and roles in service delivery. Int J Serv Ind Manage 8(3):193-205

Braun C, Wortmann F, Hafner M, Winter R (2005) Method construction-a core approach to organizational engineering. In: Proceedings of the ACM symposium on applied computing, Santa Fe, New Mexico, 13-17 March 2005

Brocke H, Hau T, Vogedes A, Schindlholzer B, Uebernickel F, Brenner W (2009) Design rules for useroriented IT service descriptions. In: Proceedings of the 42nd Hawaii international conference on system sciences (HICSS), Waikoloa, HI, 08 January 2009

Brocke H, Uebernickel F, Brenner W (2010a) Mass customizing IT-service agreements-towards individualized on-demand services. In: Alexander T, Turpin M, Deventer JPV (eds) 18th European conference on information systems (ECIS). Pretoria, South Africa

Brocke H, Uebernickel F, Brenner W (2010b) Reuse-mechanisms for mass customizing IT-service agreements. In: Proceedings of the 16th Americas conference on information systems (AMCIS). Lima, Peru, 12-15 August 2010

Brocke H, Uebernickel F, Brenner W (2011) Customizing IT service agreements as a self service by means of productized service propositions. In: Proceedings of the 44th Hawaii international conference on system sciences (HICSS). Koloa, HI, 04-07 January 2011

Bullinger H-J, Scheer A-W (2006) Service engineering: Entwicklung und Gestaltung innovativer Dienstleistungen, 2nd edn. Springer, Berlin (in German)

Bullinger H-J, Fähnrich K-P, Meiren T (2003) Service engineering: methodical development of new service products. Int J Prod Econ 85(3):275-287

Chesbrough H, Spohrer J (2006) A research manifesto for services science. Comm ACM 49(7):35-40

Constantin JA, Lusch RF (1994) Understanding resource management. The Planning Forum, Oxford, OH

Da Rold C (2009) Infrastructure utility services: the business between outsourcing and the cloud. Gartner Inc

Dan A, Davis D, Kearney R, Keller A, King R, Kuebler D, Ludwig H, Polan M, Spreizer M, Youssef A (2004) Web services on demand: WSLA-driven automated management. IBM Syst J 43(1):136-158 
Ebert C, Dumke R, Bundschuh M, Schmietendorf A (2005) Best practice in software measurement-how to use metrics to improve project and process performance. Springer, Berlin

Edvardsson B, Olsson J (1996) Key concepts for new service development. Serv Indust J 16(2):140-164 EITO (2007) European information technology observatory 2007. European Information Technology Observatory, European Economic Interest Grouping, Frankfurt, Germany

Ernest M, Nisavic JM (2007) Adding value to the IT organization with the component business model. IBM Syst J 46(3):387-403

Fettke P, Loos P (2003) Classification of reference models: a methodology and its application. Inform Syst E Bus Manage 1(1):35-53

Galbraith JR (2002) Organizing to deliver solutions. Organ Dynam 31(2):194-207

Galup SD, Dattero R, Quan JJ, Conger S (2009) An overview of IT service management. Commun ACM 52(5):124-127

Garschhammer M, Hauck R, Hegering H-G, Kempter B, Radisic I, Rolle H, Schmidt H, Langer M, Nerb M (2001a) Towards generic service management concepts: a service model based approach. In: Pavlou G, Anerousis N (eds) 7th IFIP/IEEE international symposium on integrated network management. IEEE, Seattle, WA, pp 719-732

Garschhammer M, Hauck R, Kempter B, Radisic I, Roelle H, Schmidt H (2001b) The MNM service model—refined views on generic service management. J Comm Network 3(4):297-306

Glushko RJ, Tabas L (2009) Designing service systems by bridging the "front stage" and "back stage". Inform Syst E Bus Manage 7(4):395-471

Grönroos C (2000) Service management and marketing: a customer relationship management approach. Wiley, West Sussex

Gummesson E (2000) Qualitative methods in management research, 2nd edn. Sage Publications, Thousand Oaks

Gutzwiller T (1994) Das CC RIM-Referenzmodell für den Entwurf von betrieblichen, transaktionsorientierten Informationssystemen. Physica, Heidelberg (in German)

Hegering H-G, Beck S, Neumair B (1999) Integrated management of networked systems: concepts, architectures, and their operational application. The Morgan series in networking. Morgan Kaufmann Pub, San Francisco, CA

Holub E (2009) Embracing ITSM to build a customer service provider culture in IT I\&O. Gartner Inc

ITGI (2007) Control objectives for IT and related technologies. IT Governance Institute (ITGI), Rolling Meadows

Ivens BS (2005) Flexibility in industrial service relationships: the construct, antecedents, and performance outcomes. Ind Mark Manag 34(6):566-576

Kannan PK, Proenca JF (2010) Design of service systems under variability: research issues. Inform Syst E Bus Manage 8(1):1-11

Kaplan AM, Haenlein M (2006) Toward a parsimonious definition of traditional and electronic mass customization. J Prod Innovat Manage 23(2):168-182

Kaplan J, Forrest W, Kindler N (2008) Revolutionizing data center efficiency. Uptime Institute Symposium 2008, Green Enterprise Computing, McKinsey

Karten N (2004) With service level agreements, less is more. Inform Syst Manage 21(4):43-44

Keel AJ, Orr MA, Hernandez RR, Patrocinio EA, Bouchard J (2007) From a technology-oriented to a service-oriented approach to IT management. IBM Syst J 46(3):549-564

Keller G, Nüttgens M, Scheer A-W (1992) Semantische Prozeßmodellierung auf der Grundlage "Ereignisgesteuerter Prozessketten (EPK)". Veröffentlichungen des Instituts für Wirtschaftsinformatik, University of Saarland, Saarbrücken (in German)

Kunau G, Junginger M, Herrman T, Krcmar H (2005) Ein Referenzmodell für das Service Engineering mit multiperspektivischem Ansatz. In: Herrmann T, Kleinbeck U, Krcmar H (eds) Konzepte für das service engineering-Modularisierung, Prozessgestaltung und Produktivitätsmanagement. Physica, Heidelberg, pp 187-216 (in German)

Lau F (1997) A review on the use of action research in information systems studies. In: Lee AS, Liebenau J, DeGross J (eds) Information systems and qualitative research. Chapman and Hall, London, pp 31-68

Maglio PP, Srinivasan S, Kreulen JT, Spohrer J (2006) Service systems, service scientists, SSME, and innovation. Comm ACM 49(7):81-85

Maglio PP, Vargo SL, Caswell N, Spohrer J (2009) The service system is the basic abstraction of service science. Inform Syst E Bus Manage 7(4):395-406 
Metelko J, Mueller C, Sinka I, Alili S, Blacksell T, Camoin G, Donaldson S, Edwards S, François C (2008) The role of the IT function in business innovation. Global CIO survey. Capgemini Consulting

Ng ICL, Maull R, Yip N (2009) Outcome-based Contracts as a driver for systems thinking and servicedominant logic in service science: evidence from the defence industry. Eur Manage J 27(6):377-387

O'Sullivan J, Edmond D, Ter Hofstede A (2002) What's in a service? - Towards accurate description of non-functional service properties. Distrib Parallel Databases 12(2):117-133

OGC (2007a) ITIL—service design. IT Infrastructure Library, The Stationery Office (TSO), Norwich

OGC (2007b) ITIL—service strategy. IT Infrastructure Library, The Stationery Office (TSO), Norwich

OGC (2007c) ITIL-service transition. IT Infrastructure Library, TSO, Norwich

Oliva R, Kallenberg R (2003) Managing the transition from products to services. Int J Serv Ind Manage 14(2):160-172

Österle H, Blessing D (2000) Business engineering model. In: Österle H, Winter R (eds) Business engineering. Springer, Berlin, pp 61-82

Peppard J (2003) Managing IT as a portfolio of services. Eur Manage J 21(4):467-483

Pine BJ (1993) Mass customization: the new frontier in business competition. Harvard Business School Press, Boston

Ramaswamy R (1996) Design and management of service processes: keeping customers for life. Addison-Wesley, Reading

Rands T (1992) Information technology as a service operation. J Inform Tech 7(4):189-201

Rapoport R (1970) Three dilemmas in action research. Human Relations 23(6):499-513

Rodosek GD (2003) A generic model for IT services and service management. In: Goldszmidt G, Schönwälder J (eds) 8th International symposium on integrated network management. Colorado Springs, IEEE, pp 171-184

Saltzer JH, Reed DP, Clark DD (1984) End-to-end arguments in system design. ACM Trans Comput Syst 2(4):277-288

Scheer A-W (2000) ARIS-business process modeling, 3rd edn. Springer, Berlin

Spohrer J, Maglio PP, Bailey J, Gruhl D (2007) Steps toward a science of service systems. IEEE Comput Soc 40(1):71-77

Sturm R, Morris W, Jander M (2000) Foundations of service level management. Sams, Indianapolis

Susman GI, Evered RD (1978) An assessment of the scientific merits of action research. Adm Sci Q 23(4):582-603

Thomas O, vom Brocke J (2010) A value-driven approach to the design of service-oriented information systems-making use of conceptual models. Inform Syst E Bus Manage 8(1):67-97

Tien JM, Berg D (2003) A case for service systems engineering. J Syst Sci Syst Eng 12(1):13-38

Trienekens JM, Bouman JJ, van der Zwan M (2004) Specification of service level agreements: problems, principles and practices. Software Qual J 12(1):43-57

Unterharnscheidt P, Kieninger A (2010) Service level management-challenges and their relevance from the customers' point of view. In: Proceedings of the 16th Americas conference on information systems (AMCIS). Lima, Peru, 12-15 August 2010

Vaattovaara M (1999) Transforming services into products in a systems engineering company. Helsinki University of Technology, Helsinki

Van Bon J (2007) IT service management: an introduction. Van Haren Publishing, Zaltbommel

Vargo SL, Lusch RF (2004) Evolving to a new dominant logic for marketing. J Market 68(1):1-17

Vargo SL, Lusch RF (2006) Service-dominant logic: what it is, what it is not, what it might be. In: Lusch RF, Vargo SL (eds) The service-dominant logic of marketing: dialog, debate, and directions. M.E. Sharpe Inc., Armonk, pp 43-56

Whyte WF, Greenwood DJ, Lazes P (1991) Participatory action research-through practice to science in social research. In: Whyte WF (ed) Participatory action research. Sage, Newbury Park, pp 19-55

Wikström S (1996) Value creation by company-consumer interaction. J Market Manage 12(5):359-374

Winniford MA, Conger S, Erickson-Harris L (2009) Confusion in the ranks: IT service management practice and terminology. Inform Syst Manage 26(2):153-163

Wittgreffe J, Dames M, Clark J, McDonald J (2006) End-to-end service level agreements for complex ICT solutions. BT Technol J 24(4):31-46

Zarnekow R, Brenner W, Pilgram U (2006) Integrated information management: applying successful industrial concepts in IT., 1st edn. Springer, Berlin

Zeithaml V (1988) Consumer perceptions of price, quality, and value: a means-end model and synthesis of evidence. J Market 52(3):2-22 